\title{
The Level of Reading Comprehension Skills of Students with Learning Disabilities in Jordan
}

\author{
Samir Al-Rimawi \\ Associate Professor, Department of Psychology and Special Education, \\ Princess Alia University College, Al Balqa Applied University, Jordan
}

\section{Amaal Al Masri}

Assistant Professor, Princess Alia University College, Al Balqa Applied University, Jordan

DOI: https://doi.org/10.36941/jesr-2022-0019

\begin{abstract}
The study aimed to measure the level of reading comprehension skills of students with learning difficulties in the Kasbah of As-Salt, and the study used the descriptive method on a sample of (54) male and female students chosen randomly. The reading comprehension scale was developed and prepared by Al-Mahalla and Al-Ramamneh (2019), and the results indicated that the level of reading comprehension was at an intermediate level and in all its three dimensions (literal, deductive, and creative). And the existence of statistically significant differences in the level of reading comprehension due to the variable of gender in favor of males, and there are also statistically significant differences in the level of overall reading comprehension due to the variable of the educational level of parents and in favor of holders of a bachelor's degree.
\end{abstract}

Keywords: Reading Comprehension Skills, Students with learning disabilities, Literal level, Deductive level, Creative level

\section{Introduction}

Learning difficulties are considered an ongoing condition and are presumed to result from neurological factors that interfere with the growth of verbal and nonverbal abilities. Learning difficulties are a clear disability, with normal to extraordinary mental ability, integrated sensorymotor systems, and adequate educational opportunities. This condition varies in its degree of appearance and severity, affecting a person's life self-esteem, education, professionalism, social adjustment, and daily life activities. Reading is not just a decoding of written codes but a complex process that requires understanding, linking, deduction, evaluation, problem-solving, and criticism of what he read. And before the child reaches control over the various processes, he goes through several stages, but before detailing them, we must point out that these stages are not precisely defined, as the researchers disagreed on them, but they emphasize that they are intertwined with each other and occur in an integrated context (Lattawi, 2013). 
Reading comprehension is considered the goal of reading and the desired distraction and the goal that every teacher seeks to develop the different skills of students at different school stages (Al Hallaq, 2010). Where the student performs many different mental operations such as analysis, generalization, abstraction, perception, judgment, deduction, and linking, the more an individual reads, the expansion of his intellect and talent, his horizons and culture expand, and this also depends on the style of reading itself (Al-Hamid, 2010).

Among the essential things that develop reading comprehension skills are the methods used in teaching; Because it is considered a fundamental pillar of education in adopting a specific strategy to accomplish an educational position within a specific subject. The strategy is a set of rules and principles related to a specific field and helps make decisions based on plans to achieve results as learners can understand the material's content, understand it, and apply it. (Musa, 2001) defined it. Reading comprehension is a mental process that the reader performs to deal with the text-based on previous experiences. It is a complex process that includes the reader's perception of all the information in the readable topic. Reading comprehension is inferred from answering comprehension questions, including explicit and implicit knowledge and multiple comprehension skills.

Al-Issawi and Al-Dhahani (2006) also define it as a mental process that the reader performs to interact with the written text, using his previous experiences to recognize the letters of the word, recognize the word, understand the word, understand the sentence, understand the paragraph, and infer the level of the reader's understanding, by answering the test questions that the study prepared for this purpose.

Abdul Hamid (2002) adds that it is the process of extracting meaning from the words read, as it is the derivation of the meaning from what is read, which is the comprehension of the text during reading in terms of literal, deductive, critical, tasteful and creative understanding (Nahaba, 2013).

Abdel-Hafez (2007) also defines it as the student's ability to consciously read through which he can understand and interpret meanings, identify clear and hidden ideas, arrange them, evaluate them, make judgments about the readable material and solve the cognitive problems facing him.

The importance of reading comprehension is highlighted because it is the basic structure through which the student learns and comprehends Arabic language topics. As well as the topics of other school subjects to varying degrees according to the degree of their saturation with the linguistic factor, so developing reading comprehension skills remains one of the basic goals which educators, linguists, and psychologists always seek to achieve among students with learning difficulties at all educational levels (Abdel-Wahab, 2008).

Reading comprehension skills allow reading comprehension to be reflected in the student's life, and it is the basis for learning every reading; the basic principle concerning reading is that it is first to understand and to help the student to solve problems so that the student acquires the skills of objective criticism. It allows them to express opinions, helps the student delve into the readable text, and learning from understanding remains in the learner's memory a more extended period of learning through memorization (Hafez, 2008; Al-Tatari, 2016).

Reading comprehension is an essential reading skill. It is the goal of every reading, and there is no point in any reading without understanding. The reader who can achieve the goals for which he is reading; and broadens his experiences, and he benefits from these experiences in solving his problems, controlling his language skills, and can succeed in the educational process, in addition to the breadth of his ideas, the richness of his information, and the accompanying self-confidence, and the ability to express opinion, criticism, taste, and creativity. Understanding is a student's weapon towards social, intellectual, and political primacy, and this is what makes reading comprehension the goal of every reading and the goal that every teacher seeks to develop at his various levels among his students. Its importance is evident in the following:

First: Reading comprehension is a guarantee of advancing the learner's language, providing him with rich ideas and knowledge of helpful information, acquiring critical skills in objectives, accustoming him to express an opinion, and passing judgments on the reciter with what supports it, 
and helping him to notice what is new, to face the problems he encounters, and to provide him with what allows him to be creative (Fadl, 2001).

Second: Reading comprehension is a fundamental and necessary requirement in reading, and reading comprehension is not limited to a specific academic subject, as comprehension includes all academic subjects from the Arabic language, science, mathematics, and others (Abdel-Hamid, 2002).

The foundations of reading comprehension are defined in determining the critical aspects of understanding, taking into account the time that the reader needs to read a specific text, the level of the reader's understanding to achieve the goal of reading, and investing the reader's energies and activating them to reach an understanding (Habib Allah, 200o). Brown added, as reported by Sultana (2006), that reading comprehension starts from identifying important aspects of understanding, focusing attention on the main idea rather than focusing on secondary ideas, observing existing activities, to determine whether the goal is occurring, and taking appropriate action when deficiencies in the understanding process are observed.

The classification of comprehension skills to levels faced many criticisms due to the great overlap between those levels. Therefore Aukerman \& Aukerman suggested classifying comprehension skills into patterns, and in these patterns, each style is closely related to the other, and emphasis is placed on how the understanding is made, and these patterns are equal in importance. Thus, these two scientists have classified comprehension skills into six styles: the literal style, the inferential pattern, the assimilation pattern, the applied pattern, the critical pattern, and the emotional pattern (Mafleh, 2005).

Accordingly, the reading comprehension skills were classified according to what was reported by Nagah and Hafez (2002) as follows:

1. Literal comprehension: Identify lexical and idiomatic terms, identify and remember details, recognize ideas declared in the text, and follow instructions.

2. Inferential understanding: By deducing similarities and differences, deducing cause-effect relationships, inferring implicit meanings in the text, deducing the writer's purposes and motives.

3. Creative understanding: It means responding to the topic, trying to simulate it, adding and supplementing (providing suggestions and alternative solutions that can lead to better results) and solving similar problems based on the readable material, adding a comment, completing a text, and build a creative opinion.

Many factors can affect the reader's ability to understand the readable, such as the reader's availability of the goal and the nature, tribal knowledge of the subject matter of the text, the strategy used by the reader in the reading comprehension of the text, directing questions before or after the reading process, linking ideas with each other within a single text, the level of the reader's motivation and attraction to reading the topic, and the level of the reader's ability to comprehend and master his skills (Al-Dulaimi \& Al-Waeli, 2009).

The topic of reading comprehension for students with learning difficulties has received the attention of researchers. First, and that is that a great deal of school learning depends on the ability to read, we find that the most common types of academic difficulties are for those with learning difficulties in reading, as reading is the primary means for all academic inputs. The scholars also believe that $71: 78 \%$ of the school children population suffer from reading difficulties (Awadallah and Ashour, 2003).

It is defined as a delay, disorder, or stunted growth in one or more of the processes of speaking and communication, language, reading, writing, arithmetic, or any other study subject resulting from a psychological disability, or arise from all of or at least one of brain dysfunction or behavioral or emotional disorders. At the same time, it is not the result of mental retardation, sensory disability, or cultural, teaching, or educational factors (Learner, 2003).

They are those who suffer from deficits in one or more of the processes of speech, language, reading, spelling, writing, and arithmetic as a result of a possible defect in the function of the brain or an emotional or behavioral disorder, but it is not the result of mental retardation (Al-Batayneh, 
Ghawanimah, Al-Jarrah, 2009).

The factors causing learning difficulties are the group of external acquired injuries that lead to damage to the central nervous system, and it creates learning difficulties, these injuries may occur before, during, or after birth, or due to a combination of genetic factors as they play a significant role in causing learning difficulties, these factors can be direct and indirect. The direct ones are those that are transmitted from parents to children, and the indirect ones are the ones that result from a defect during embryonic formation (Alwaqfi, 2003).

Chemical factors may cause it through the presence of a cellular chemical anomaly based on an imbalance in the production of neurotransmitters that transmit nerve impulses from one brain cell to another. The environmental factors are summarized in the early forms of environmental deprivation of sensory and psychological stimuli that the child does not receive naturally (Abu Al-Fakhr, 2004).

They can be classified into two general categories: developmental learning difficulties in basic psychological functions, including attention, memory, thinking, and oral language, and academic difficulties in expressive reading and writing, including spelling and arithmetic (Adeniyi, 2009 \& Fakoladc).

Difficulties learning to read have a different impact according to the individual. And the impact of the difficulty depends on its severity and on the success of educational efforts made to overcome it (Mahmoud, 2013).

According to the research, the researcher did not find studies related to the subject of the study, as Al-Makhalla and Al-Ramamneh (2019) conducted a study to know the effect of Robinson's strategy on improving reading comprehension skills of students with learning difficulties at the sixth-grade level. An achievement test was built to measure reading comprehension skills (literal, deductive, applied, and creative) on a sample of (40) students randomly selected from the sixth grade, and the results indicated that there were differences in the reading comprehension skills of students on the post-measurement according to the teaching method in favor of the experimental group. However, there were no differences between the experimental and control group due to the variable of sex.

Flossy (2015) studied the relationship between reading comprehension and the ability to solve mathematical problems, a comparative study between ordinary students and those with academic learning difficulties (reading - mathematics) in light of the gender variable. And the relational descriptive approach was used, and the study sample consisted of (524) experienced students in the third year of primary school. The results showed a correlation between the reading comprehension test scores and the mathematical problems test scores of the total sample students. And the absence of a relationship between reading comprehension and mathematical problems among the sample of ordinary students, and the existence of a correlation between reading comprehension and mathematical problems for those with academic learning difficulties (reading and mathematics).

Dharma \& Abdullah (2013) conducted a study aimed to describe the use of the (SQ3 $\mathrm{R}$ ) strategy as a strategy for teaching the skill of reading and to understand and absorb readable texts of tenthgrade students; the two researchers used the observation card and questionnaire to achieve the objectives of the study. The results often indicated that the ( $\left.\mathrm{SQ}_{3} \mathrm{R}\right)$ strategy benefited the student in understanding the readable text and increasing their reading ability. Furthermore, the results showed an agreement in the student's views on the importance of this strategy in teaching reading, and the researchers suggested the need to use this strategy because it helps reading and to understand together.

Komang et al. (2013) conducted a study that aimed to determine the interaction between the PQRST strategy and the $\mathrm{SQ}_{3} \mathrm{R}$ strategy for reading adequacy based on text type for eighth-grade students in Indonesia. As a result, they reached (179), the study results indicated that there are differences between the two methods and in favor of the PQRST method, and there is no interaction effect between the two methods based on the nature of the text.

Souvignier and Antoniou (2007) study the teaching of reading comprehension through strategies, a therapeutic study for students with learning difficulties; the sample consisted of (73) students from the fifth to the eighth grades, where special education teachers taught this group. The 
pre-test, post-test, and follow-up designs were used over a full year to assess reading skills, reading comprehension, and self-efficacy. After the end of the school year, an effect of the program on developing reading skills was observed, and upon follow-up, improvements were found in reading comprehension, reading skills, and self-regulation skills for reading.

\subsection{Commenting on previous studies}

The current study was distinguished in its approach to an important group of students who have learning difficulties about reading comprehension, and the current study combined its tools between testing and observation. The study also clarified the differences in reading comprehension skills among students of learning difficulties in the Kasbah of As-Salt and their relationship to some demographic variables such as gender and the parent's educational level. As for previous studies, they dealt with reading comprehension from several aspects: Some of them conducted a study to find out the extent of teaching reading comprehension through strategies, a therapeutic study for students with learning difficulties as the study of Souvignier and Antoniou (2007), and some of them conducted it to find out the relationship between reading comprehension and the ability to solve mathematical problems, a comparative study between ordinary students and those with academic learning difficulties (reading - mathematics) in light of the gender variable. As Flossy's study (2015), and some of them conducted a study to find out the interactive effect between the PQRST strategy and the $\mathrm{SQ}_{3} \mathrm{R}$ strategy for reading adequacy based on the type of text As a study Komang et al. (2013) furthermore, as of them conducted a study to describe the use of the strategy $\left(\mathrm{SQ}_{3} \mathrm{R}\right)$ as a strategy for teaching the skill of reading and understanding and comprehending the read texts. In addition to identifying students' $\mathrm{r}$ et al.ses towards this strategy, such as the study of Dharma and Abdullah (2013).

There were differences of samples in previous studies that dealt with reading comprehension. Some of them conducted their studies on middle school students as a study Komang et al. (2013); And Dharma \& Abdullah (2013), Some of them conducted it on primary stage students, such as Firdaus (2012); Al-Makhalla and Al-Ramamneh (2019); Felousi (2015); Souvignier and Antoniou (2007), AlAbdalat and Al-Samadi (2016). The study sample size for previous studies ranged between (30-524), and the researcher benefited from that in determining the size of the study sample.

\subsection{The study problem and its questions}

The study problem is represented in the poor level of students with learning difficulties in the basic stage in reading in general and reading comprehension in particular. This leads to some problems associated with these students, including poor performance on reading comprehension skills; this may be due to many factors related to teaching reading and teaching skills and the teaching strategies used to treat these difficulties, students with difficulties in learning and understanding reading face as one of the most important goals of the educational process. Teaching reading aims to develop the individual's ability to understand what is in the printed material. Whereas real reading is reading associated with comprehension, as research results have demonstrated a close relationship between good reading and comprehension, it is known that students with learning disabilities face difficulty in reading aloud and comprehension. They do not learn by the methods used in the regular class.

Students with learning difficulties in reading face problems understanding what they read, linking ideas, and difficulty understanding between the lines. The most educational difficulties are represented in reading skills, which is considered one of the most important skills students with learning difficulties need in school and their lives because of their direct relationship and impact on other subjects. And this requires special teaching methods that help them overcome the difficulties they suffer from because they do not learn by normal methods. The researcher also noted that there are deficiencies related to teaching reading for this group at this stage, which resulted in a weakness in the students' level of reading comprehension skills, and therefore this study came to answer the 
following questions:

- What is the level of reading comprehension skills among fifth-grade students with learning difficulties?

- Are there statistically significant differences in the level of reading comprehension skills among students with learning difficulties in the fifth grade due to the variable (gender, educational level of parents)?

\subsection{The importance of the study}

The importance of the current study stems from the importance and benefits of the reading comprehension process, as it is considered the key to science and knowledge; reading is considered one of the acquired skills that an individual need, which leads to achieving success and developing knowledge and abilities. The study also gains its importance from the theoretical and practical sides, as shown in the following:

1. The study gains importance in its results when designing and developing training programs for students with learning difficulties on the importance of reading comprehension skills.

2. Open the door for researchers and scholars to conduct future studies in this field, relying on the current study results and the recommendations it will present.

3. The researcher hopes to benefit from the research results in determining the reading comprehension skills of students with learning difficulties.

4. Contribute to the enrichment of one of the important areas in psychological and cognitive studies, which is the level of reading comprehension skills among students with learning difficulties.

5. Direct the attention of officials in the Ministry of Education in Jordan to the importance of disclosing it and directing their administrative practices in light of this.

\section{$1.4 \quad$ The Study objectives}

The study aims to clarify the concept of reading comprehension skills, and to know the level of reading comprehension skills of the study sample, and whether there are differences in the level of reading comprehension skills of students with learning difficulties due to a variable (gender, educational level of parents).

\subsection{Procedural Definition of Terms}

\subsubsection{Reading comprehension skills}

One of the language skills that require the individual to use different cognitive processes to access the meanings in the reading texts (Ghelani, Sidu, Jain, Tannock, 2004).

It is defined procedurally: the degree obtained by the study sample through their response to the paragraphs of the study scale.

\subsubsection{Learning difficulties students}

They are students who suffer from disorders in one or more of the basic psychological processes, which include understanding and using written or spoken language, problems with listening, thinking, speaking, reading, writing, and mathematics appear, provided that the difficulties are not due to causes related to mental, auditory, or family impairment or other types of disabilities or learning conditions or family care (Lerner, 2003). 


\subsection{The Study limits}

The limits of the current study are as follows:

Human, spatial and temporal limits: All students with learning difficulties at the fifth-grade level in the city of Al-Salt, the Hashemite Kingdom of Jordan / Balqa Governorate / Qasabat Al-Salt Brigade, in 2019 .

\subsection{Limitations of the study}

The generalization of the results depends on the sample characteristics and the degree of its representation of the society it was taken from, the study tools, and their dimensions and psychometric characteristics.

\section{The Study Methodology}

The researcher used the descriptive approach, using survey studies, for its relevance to the study objectives and questions.

\subsection{The Study Population and Sample}

The study population consisted of all students with learning difficulties in the Qasabat al-Salt Brigade in the Balqa Governorate, whose number is (62) male and female students, distributed over (16) schools for males, and (13) schools for females in the government sector. As for the study sample, and due to the small size of the study population, the entire population of the study was chosen, so that the final sample on which the questionnaires were distributed consisted of (62) male and female students, and the number of questionnaires returned after the distribution process reached (54), as the questionnaires that were not filled out correctly and completely were excluded, and Table (1) illustrates this.

Table 1: The study sample is distributed according to the study variables

\begin{tabular}{|l|l|c|c|}
\hline Variable & Variable classes & The study sample & Percentage \\
\hline \multirow{3}{*}{ Gender } & Male & 34 & $\% 63$ \\
\cline { 2 - 4 } & Female & 20 & $\% 37$ \\
\cline { 2 - 4 } & Total & 54 & $\% 100$ \\
\hline \multirow{3}{*}{ Parents' educational level } & Diploma & 8 & $\% 15$ \\
\cline { 2 - 4 } & Bachelor & 29 & $\% 54$ \\
\cline { 2 - 4 } & Postgraduate & 17 & $\% 31$ \\
\hline \multicolumn{2}{|l}{ Total } & 54 & $\% 100$ \\
\hline
\end{tabular}

\subsection{The Study Tool}

\subsubsection{Reading Comprehension Level Scale}

Regarding literature and previous studies related to the subject of the study and some reading comprehension tests, the reading comprehension scale prepared by Al-Mahalla and Al-Ramamneh (2019) was adopted and developed for sixth-grade students with learning difficulties. In its final form, the scale consists of (15) items distributed on three dimensions: literal understanding (5) paragraphs, deductive understanding (5) paragraphs, and creative understanding (5) paragraphs. It was presented to a group of specialized professors for arbitration, and based on their comments, no paragraph was deleted from the scale paragraphs, but rather the wording of some paragraphs was modified without 
deleting any of them. As a result, and in light of the experts' opinions, some linguistic amendments were made to some of the paragraphs, and the scale consisted in its final form of (15) paragraphs without deleting any paragraph of the scale. It is of the self-report that the teachers answer in light of the five-step scale: Strongly agree (5), Agree (4), Neutral (3), Disagree (2) Strongly Disagree (1), and the following equation was used to extract the range for each of the three levels: (the upper class - the lower class) that is, (1-5) divided by (3) equals (1.33), and therefore: from (1-2.33) a low level, and (2.34-3.67) a medium level, and (3.68-5) a high level. The paragraph's correlation coefficients were extracted on the overall scale and in the dimension to which they belong to extract the indications of the validity of the scale's internal consistency. The paragraphs correlation coefficients with the tool as a whole ranged between (0.384 - 0.729), and with the distance between (0.379 - 0.742), and Table (2) shows that:

Table 2: Correlation coefficients between paragraphs, the dimension to which they belong, and the overall score on the Reading Comprehension Skills Scale

\begin{tabular}{|l|l|l|l|l|l|l|l|l|}
\hline $\begin{array}{l}\text { Item } \\
\text { number }\end{array}$ & $\begin{array}{l}\text { Correlation } \\
\text { with the } \\
\text { tool }\end{array}$ & $\begin{array}{l}\text { Correlation } \\
\text { with the } \\
\text { dimension }\end{array}$ & $\begin{array}{l}\text { Item } \\
\text { number }\end{array}$ & $\begin{array}{l}\text { Correlation } \\
\text { with the } \\
\text { tool }\end{array}$ & $\begin{array}{l}\text { Correlation } \\
\text { with the } \\
\text { dimension }\end{array}$ & $\begin{array}{l}\text { Item } \\
\text { number }\end{array}$ & $\begin{array}{l}\text { Correlation } \\
\text { with the } \\
\text { tool }\end{array}$ & $\begin{array}{l}\text { Correlation } \\
\text { with the } \\
\text { dimension }\end{array}$ \\
\hline 1 & $0.729^{* *}$ & $.512^{* *}$ & $\mathbf{6}$ & $0.734^{*}$ & $.621^{* *}$ & $\mathbf{1 1}$ & $.396^{*}$ & $.479^{* *}$ \\
\hline $\mathbf{2}$ & $.513^{* *}$ & $.420^{*}$ & $\mathbf{7}$ & $.384^{*}$ & $.441^{*}$ & $\mathbf{1 2}$ & $.419^{*}$ & $.432^{*}$ \\
\hline 3 & $.389^{*}$ & $.579^{*}$ & $\mathbf{8}$ & $.418^{*}$ & $.384^{*}$ & $\mathbf{1 3}$ & $.426^{*}$ & $.653^{* *}$ \\
\hline 4 & $.546^{* *}$ & $.379^{*}$ & $\mathbf{9}$ & $.613^{* *}$ & $.593^{* *}$ & $\mathbf{1 4}$ & $.459^{* *}$ & $.472^{* *}$ \\
\hline 5 & $.429^{*}$ & $.682^{* *}$ & $\mathbf{1 0}$ & $.569^{* *}$ & $.419^{*}$ & $\mathbf{1 5}$ & $.424^{*}$ & $.742^{* *}$ \\
\hline
\end{tabular}
significance (o.01).
Statistical significance at the level of significance (o.05). ${ }^{* *}$ Statistical significance at the level of

It is evident from Table (2) that the items' correlation coefficients with the total degree and the dimension to which they belong were statistically significant at the significance levels $\alpha=(0.05)$ and (o.o1), so none of them was omitted. This indicates that the scale is suitable for measuring the level of reading comprehension, and this indicates that the scale has high validity and is appropriate for the current study.

To verify the stability of the scale, the test-retest and the Cronbach Alpha method were used so that the internal consistency factor of the overall scale in the Cronbach alpha method reached (0.85) while it reached ( 0.87 ) by the method of constant repetition. Table (3) shows the stability coefficients for the dimensions of the reading skills scale by the two methods of stability of repetition and Cronbach alpha, which are high and acceptable coefficients for the study's purposes, which supports the use of this scale in the current study.

Table 3: Coefficients for the stability of the reading comprehension skills scale in the alpha and repetition methods

\section{Dimensions}

Literal understanding

Deductive understanding

Creative understanding

Total Reading Comprehension

Test/retest reliability
0.86
0.82
0.84
0.85

0.85

Cronbach Alpha
0.81
0.80
0.82
0.82

\section{The Study Results and its Discussion}

The first question: What is the level of reading comprehension skills for fifth-grade students among students with learning difficulties?

To answer this question, the arithmetic average and standard deviations of the responses of the 
fifth-grade students of learning difficulties were extracted on the four dimensions of the reading comprehension level scale, shown in Table (4):

Table 4: The averages and standard deviations of the four domains of the Reading Comprehension Level scale

\begin{tabular}{|c|c|c|c|c|c|c|}
\hline Item number & Dimensions & $\begin{array}{l}\text { Standard } \\
\text { deviation }\end{array}$ & $\begin{array}{c}\text { Arithmetic } \\
\text { average }\end{array}$ & Repetition & Rank & Level \\
\hline 1 & Literal understanding & 0.82 & 2.96 & 54 & 1 & Moderate \\
\hline 2 & Deductive understanding & 0.91 & 2.75 & 54 & 2 & Moderate \\
\hline 4 & Creative understanding & 0.93 & 2.67 & 54 & 3 & Moderate \\
\hline \multicolumn{3}{|c|}{ The total score for the level of reading comprehension } & .86 & 2.73 & 54 & Moderate \\
\hline
\end{tabular}

Table (4) shows that the highest average reached (2.96) for the literal comprehension dimension with a standard deviation (o.82) and at a medium level, and the lowest for the average creative understanding dimension with a mean (2.67) and a standard deviation (o.93) and a medium level, and the total reached (2.73) with a standard deviation (86) and a medium level.

The result can be explained that the teaching methods used in public schools may be somewhat unconventional so that it targets students with learning difficulties, and it uses many methods of reading and organized steps that suit their needs and abilities. It opens the way for them to organize information and find new ways to scan, remember and review information. As a result, they increase motivation and enhance their performance, improving reading comprehension, increasing activity, memorization, interacting with and thinking about the written text, and connecting ideas, which adds an atmosphere of fun and challenge.

The interest by teachers may allow the attention of students with learning difficulties to focus on the salient points and elements in the readable material, and it allows the practice of thinking methods related to the ideas and meanings involved. Monitoring mental and linguistic activities are used to verify understanding, allowing them to follow the sequence within steps by linking previous experiences with the present. The repeated implementation of the educational task to reach perfection helps transmit the impact of learning efficiently, and the result is consistent with the study of both Al-Mkahalla and Al-Ramamneh (2019) and Flossy (2015).

The second question: Are there statistically significant differences in the level of reading comprehension skills among students with learning difficulties in the fifth grade due to a variable (gender, parents' educational level)?

To answer this question, the mean and standard deviations of the study sample were calculated according to two variables, and Table (5) indicates that.

Table 5: The arithmetic means and standard deviations of the dimensions of the gender variable and parents' educational level

\begin{tabular}{|l|l|c|c|c|c|}
\hline Variables & Number & Arithmetic average & standard deviation & Rank \\
\hline \multirow{3}{*}{ Gender } & Male & 34 & 3.47 & .77 & 1 \\
\cline { 2 - 6 } & Female & 20 & 3.21 & .63 & 2 \\
\hline \multirow{3}{*}{ Parents' educational level } & Diploma & 8 & 3.06 & .56 & 3 \\
\cline { 2 - 7 } & Bachelor & 29 & 3.43 & .76 & 1 \\
\cline { 2 - 6 } & Postgraduate & 17 & 3.28 & .63 & 2 \\
\hline
\end{tabular}

It is clear from Table (6) that there are apparent differences concerning the variables of gender and Parents' educational level.

To verify the statistical significance of the differences between the arithmetic averages in the level of reading comprehension among the study sample, the binary analysis of variance test was conducted, and Table (7) explains that: 
Table 7: Analysis of binary variance of differences in the level of reading comprehension among the study sample according to the gender variables and Parents' educational level

\begin{tabular}{|l|c|c|c|c|c|}
\hline \multicolumn{1}{|c|}{ Source } & Sum of squares & Degrees of freedom & $\begin{array}{c}\text { Average of } \\
\text { squares }\end{array}$ & P-value & $\begin{array}{c}\text { Statistical } \\
\text { significance }\end{array}$ \\
\hline Gender & 1.329 & 1 & .675 & 4.162 & ${ }^{* *} .004$ \\
\hline $\begin{array}{l}\text { Parents' educational } \\
\text { level }\end{array}$ & 1.562 & 2 & .792 & 5.136 & ${ }^{* *} .003$ \\
\hline
\end{tabular}

${ }^{* *}$ statistically significant at the level of significance $(\alpha=0.01)$

It is evident from Table (7) that there are differences in the level of reading comprehension due to the variable of gender and in favor of males, and to the variable of the educational level of parents and in favor of holders of a bachelor's degree.

Accordingly, a Shave test was performed for the dimensional comparisons to show the differences between the educational level variable of the parents (diploma, bachelor's, graduate studies) at the level of reading comprehension, and the tables show that (8).

Table 8: Scheffe test to measure the effect of parents 'educational level on overall reading comprehension

\begin{tabular}{|c|c|c|c|c|c|c|}
\hline \multirow{2}{*}{$\begin{array}{c}\text { (I) Parents' } \\
\text { educational level }\end{array}$} & \multirow{2}{*}{$\begin{array}{c}\text { (J) Parents' } \\
\text { educational level }\end{array}$} & \multicolumn{2}{|c|}{$\begin{array}{l}\text { 95\% Confidence } \\
\text { Interval }\end{array}$} & \multirow[t]{2}{*}{ Function } & \multirow{2}{*}{$\begin{array}{l}\text { The standard } \\
\text { deviation error }\end{array}$} & \multirow{2}{*}{$\begin{array}{c}\text { Difference of } \\
\text { averages }\end{array}$} \\
\hline & & Highest & Lowest & & & \\
\hline \multirow[t]{2}{*}{ Diploma } & Bachelor & .0496 & .8641 & .02 & .16495 & $.45686^{*}$ \\
\hline & Postgraduate & .0222 & .6908 & .07 & .14440 & .33428 \\
\hline \multirow[t]{2}{*}{ Bachelor } & Diploma & .0496 & .8641 & .02 & .16495 & $.45686^{*}$ \\
\hline & Postgraduate & .1742 & .4194 & .59 & 12020 & .12257 \\
\hline \multirow[t]{2}{*}{ Postgraduate } & Diploma & .0222 & .6908 & .07 & .14440 & .33428 \\
\hline & Bachelor & .1742 & .4194 & .59 & .12020 & .12257 \\
\hline
\end{tabular}

Table (8) indicates the following:

1. The differences in the arithmetic mean between the families of students with learning difficulties who hold a diploma and hold a bachelor's degree reached (046), and the value of the statistical function is (o.02). Thus, it is statistically significant, being less than (0.05), and for the benefit of the families of students with learning difficulties for those with a bachelor's degree, for obtaining the highest arithmetic average of (3.43), that is, there are statistically significant differences in the level of overall reading comprehension due to the variable of the educational level of parents and in favor of holders of a bachelor's degree.

2. The differences in the arithmetic mean between the families of students with learning difficulties who hold a diploma and holders of a postgraduate certificate reached (0.33), and the value of the statistical function is (0.07). Therefore it is not statistically significant as it is greater than (0.05).

3. The differences in the arithmetic mean between the families of students with learning difficulties who hold a postgraduate degree and hold a bachelor's degree are not statistically significant, greater than (0.05).

\section{Recommendations}

Include practical training and teacher preparation programs before and during the service in special education and higher diplomas in learning difficulties in reading, as it is the most common category of learning difficulties, to learn different academic subjects.

Include many training strategies for students with learning disabilities on cognitive and 
metacognitive skills, which helps the student's independence in reading comprehension skills. Add many cognitive skills to training strategies for students with learning difficulties that help the student in reading comprehension skills.

\section{References}

Abdel-Hafez, F. (2007). The Effectiveness of Using a Self-Directed Questioning Strategy in Teaching Reading to Develop Reading Comprehension and Critical Thinking among High School Students, Journal of the College of Education in Fayoum, 1(7): pp. 101-165.

Abdel-Wahab, A. (2008). The Impact of Training on Metacognition Strategies in Collaborative Situations in Developing Reading Comprehension Skills for Students with Learning Difficulties in Elementary Stage, Reading and Knowledge Journal - Ain Shams University, 1(81): pp. 94-177.

Abdul Hamid, A. (2002). A proposed treatment program to overcome reading comprehension difficulties among first-grade middle school students, Reading and Knowledge Magazine, Issue (124), pp. 79-124.

Abu Fakhr, G. (2004). Special Education for the Child. Damascus University Publications, Damascus.

Al Naga, M. \& Hafez, W. (2002). Teaching Arabic: Its Interventions and Techniques, Cairo: Ain Shams University.

Al Waqi, R. (2003). Theoretical and Applied Learning Difficulties. Princess Tharwat College Publications, Amman. First edition.

Al-Abdallat, B. \& Al-Samadi, J. (2016). A comparison of the effectiveness of the two strategies of direct and reciprocal teaching in improving reading comprehension skills of students with learning difficulties in reading (dyslexia), studies for Educational Sciences, 43 (1): pp. 525-547.

Al-Atwi, S. (2013). Reading Comprehension, Its Strategies and Learning Difficulties, Journal of Psychological and Educational Studies, Laboratory for the Development of Psychological and Educational Practices, Issue (11), 147-160.

Al-Batayneh, O., Gawanameh, Mamoun and Jarrah, Abdel Nasser (2009), Psychology of the Extraordinary Child, Dar Al-Masirah, Amman.

Al-Dulaimi, T.; Al-Waeli, S. \& Abdul-Karim, R. (2009). Modern Trends in Teaching the Arabic Language, Amman: The World Book Wall.

Al-Essawi, J. \& Al-Dhahani, M. (2006). The development of reading comprehension levels among seventh-grade pupils in the basic education stage in the United Arab Emirates. Journal of Studies in Curricula and Teaching Methods, 1(114): pp. 107-158.

Al-Hallaq, A. (2010). Teaching Arabic Language Skills and its Sciences, Modern Book Foundation, Tripoli, Lebanon.

Al-Hamid, H. (2010). The effectiveness of a story-based program in developing some creative reading skills among third-grade intermediate students, unpublished master's thesis, Umm Al-Qura University, Saudi Arabia.

Al-Makahlah, A. \& Rammaneh, A. (2019). The Effect of a Program Based on the SQ3R Strategy on Improving Reading Comprehension Skills for Students with Learning Difficulties in Sixth Grade, An-Najah University Journal for Research (Human Sciences), 33(2): pp. 275-304.

Al-Tatari, M. (2016). The effect of employing digital stories on developing reading comprehension skills among third-grade students, unpublished master's thesis, Islamic University, Gaza, Palestine.

Antoniou, F. \& Souvignier, E. (2007). Strategy Instruction in Reading Comprehension, An Intervention Study for Comprehension: A Teaching Model for Grades 3-8. Newark DE: The International Reading Association, Inc.

Awad Allah, M., Ashour, M., \& Muhammad, A. (2003). Learning Difficulties, Diagnosis, and Treatment, Amman: Arab Thought House.

Dharma, S. \& Abdullah, S. (2013). The SQ3 R Strategy to Teach Reading News Item Text to Tenth Grade Students of Senior High School, Faculty of Language and Art, State University of Surabaya.

Fadlallah, M. (2001). Levels of reading comprehension and skills required for questions in Arabic language books at the stages of general education in the United Arab Emirates, Reading and Knowledge Magazine, Issue (7), pp. 77-133.

Fakolade, O., Adeniyi, S. \& Tella, A. (2009). Attitudes of Teachers Toward the Inclusion of Special Needs children In General Education Classroom. International Electronic Journal Of Elementary Education, Vol.1, Issue 3.

Flossi, S. (2015). Reading comprehension and its relationship to the ability to solve mathematical problems, a comparative study between ordinary students and students with academic learning difficulties (reading mathematics) in the light of the variable of gender, unpublished Ph.D. thesis, Hajj Akhdar University Batna, Algeria.

Ghelani, K. Sidu, J. \& Tannock, C. (2004). Reading comprehension and reading-related abilities in adolescents with reading disabilities and attention-deficit/hyperactivity disorder. Ontario Institute for Studies in Education, The University of Toronto, Toronto, Canada. 
Habib Allah, M. (200o), Foundations of reading and reading comprehension between theory and practice. (3), Amman: Dar Ammar.

Hafez, W. (2008). The effectiveness of using the collective, cooperative education strategy and the (K-W-L) strategy in developing reading comprehension skills for sixth-grade students in the Kingdom of Saudi Arabia, Reading and Knowledge Magazine - Ain Shams University, Issue (74), pp. 153-227.

Komang et al. (2013). A Comparative Study of PQRST and SQ3 R Strategies Based on the Text Types upon the Eighth Grade Student' Reading Competency at Smpn4 Singaraja. Language Education Department. PostGraduate Program Ganesha, University of Education, Singaraja.

Lerner, J. (2003). Learning Disabilities, Theories, and Diagnoses and Teaching Strategies. Houghton Mifflin Company, U.S.A.

Mahmoud, A. (2013). The Effectiveness of the Modeling and Summarization Strategies in Treating Reading Comprehension Difficulties and Reducing Reading Anxiety in Girl-Friendly Schools Students, International Journal of Educational Research / United Arab Emirates University, 1(31): pp. 220-258.

Mofleh, G. (2005). The Effectiveness of Cooperative Learning in Developing Some Reading Comprehension Skills among First-Grade Secondary Students, Damascus University Journal, 21(2): pp. 269-302.

Moussa, M. (2001). The Impact of Metacognition Strategy in Improving Reading Comprehension and Metacognition Awareness and Question Production among Preparatory School Students, The First Scientific Conference of the Egyptian Society for Reading and Knowledge (The Role of Reading in Learning Different Subjects). Cairo Egypt.

Nahaba, A. (2013). The Impact of Self-Inquiry Strategy on Developing Reading Comprehension Skills among Second Intermediate Students, Journal of the College of Education - University of Babylon, Issue (14), pp. 101-125.

Shehata, H. \& Al-Samman, M. (2012). The reference in teaching and learning the Arabic language. Edition (1), Cairo: Arab House Book Library.

Sultana, S. (2006). The Effect of Some Mental Processes Accompanying the Recognition on Reading Comprehension of Second Intermediate Grade Students and Their Written Expression, Unpublished Ph.D. Thesis, Helwan University, Helwan, Egypt.

\section{Appendix 1: Reading comprehension skills scale}

\begin{tabular}{|l|l|l|l|l|l|l|}
\hline \multicolumn{2}{|c|}{ The literal comprehension dimension } & $\begin{array}{c}\text { Strongly } \\
\text { agree }\end{array}$ & Agree & Neutral & Disagree & $\begin{array}{c}\text { Strongly } \\
\text { Disagree }\end{array}$ \\
\hline 1. & $\begin{array}{l}\text { I can determine the appropriate meaning of } \\
\text { the word from the context. }\end{array}$ & & & & \\
\hline 2. & I can determine the antithesis of the word. & & & & & \\
\hline 3. & $\begin{array}{l}\text { I can distinguish between number forms } \\
\text { (singular, dual, and plural) }\end{array}$ & & & & \\
\hline 4. & $\begin{array}{l}\text { I can specify the names of the characters } \\
\text { mentioned in the readable. }\end{array}$ & & & & \\
\hline 5. & $\begin{array}{l}\text { I can determine the times and places } \\
\text { mentioned in the readable. }\end{array}$ & & & & \\
\hline$\quad$ The inferential understanding dimension & & & & \\
\hline 6. & Deduce the main idea in the readable. & & & & \\
\hline 7. & Deduce sub-ideas for the reading paragraphs & & & & \\
\hline 8. & $\begin{array}{l}\text { Deduce the emotion that controlling } \\
\text { readability }\end{array}$ & & & & & \\
\hline 9. & $\begin{array}{l}\text { Deduce the characteristics of the characters } \\
\text { mentioned in the readable. }\end{array}$ & & & & & \\
\hline 10. & Deduce the values contained in the readable. & & & & \\
\hline The creative understanding dimension & & & & & \\
\hline 11. & I can recap the readable text. & & & & \\
\hline 12. & $\begin{array}{l}\text { I can deduce lessons learned from the readable } \\
\text { text. }\end{array}$ & & & & & \\
\hline 13. & I can ask questions in the readable content. & & & & \\
\hline 14. & I can summarize the readable text. \\
\hline 15. & $\begin{array}{l}\text { I can explain a paragraph of the text read or all } \\
\text { of it. }\end{array}$ & & & & & \\
\hline
\end{tabular}

